\title{
Relationship of annual change in bone mineral density with extent of emphysematous lesions and pulmonary function in patients with COPD
}

This article was published in the following Dove Press journal: International Journal of COPD

\author{
Kenichi Goto, ${ }^{1,2}$ Emiko \\ Ogawa, ${ }^{1,3}$ Kaoruko \\ Shimizu, ${ }^{4}$ Hironi Makita, ${ }^{4}$ \\ Hidenobu Suzuki, ${ }^{5}$ Yoshiki \\ Kawata, ${ }^{5}$ Noboru Niki, ${ }^{5}$ \\ Masaharu Nishimura, ${ }^{4}$ \\ Yasutaka Nakano' \\ 'Division of Respiratory Medicine, \\ Department of Medicine, Shiga \\ University of Medical Science, Otsu, \\ Shiga, ${ }^{2}$ Department of Pulmonary \\ Medicine, Takatsuki Red Cross \\ Hospital, Takatsuki, Osaka, ${ }^{3} \mathrm{Health}$ \\ Administration Center, Shiga \\ University of Medical Science, \\ Otsu, Shiga, ${ }^{4}$ First Department of \\ Medicine, Hokkaido University \\ Hospital, Sapporo, Hokkaido, \\ ${ }^{5}$ Institute of Technology and Science, \\ Tokushima University, Tokushima, \\ Tokushima, Japan
}

Background: Osteoporosis is a well-known comorbidity in COPD. It is associated with poor health status and prognosis. Although the exact pathomechanisms are unclear, osteoporosis is suggested to be either a comorbidity due to shared risk factors with COPD or a systematic effect of COPD with a cause-effect relationship. This study aimed to evaluate whether progression of osteoporosis is synchronized with that of COPD.

Materials and methods: Data from 103 patients with COPD included in the Hokkaido COPD cohort study were analyzed. Computed tomography (CT) attenuation values of thoracic vertebrae 4, 7, and 10 were measured using custom software, and the average value (average bone density; $\mathrm{ABD}_{4,7,10}$ ) was calculated. The percentage of low attenuation volume (LAV\%) for each patient was also calculated for evaluation of emphysematous lesions. Annual change in thoracic vertebral CT attenuation, which is strongly correlated with dual-energy X-ray absorptiometry-measured bone mineral density, was compared with that in $\mathrm{FEV}_{1.0}$ or emphysematous lesions.

Results: In the first CT data set, $\mathrm{ABD}_{4,7,10}$ was significantly correlated with age $(\rho=-0.331$; $p=0.0006$ ), body mass index (BMI; $\rho=0.246 ; p=0.0136$ ), St George's Respiratory Questionnaire (SGRQ) activity score $(\rho=-0.248 ; p=0.0115)$, eosinophil count $(\rho=0.229 ; p=0.0198)$, and LAV\% $(\rho=-0.372 ; p=0.0001)$. However, $\mathrm{ABD}_{4,7,10}$ was not associated with $\mathrm{FEV}_{1.0}$. After adjustment for age, BMI, SGRQ activity score, and eosinophil count, no significant relationship was found between $\mathrm{ABD}_{4,7,10}$ and $\mathrm{LAV} \%$. Annual change in $\mathrm{ABD}_{4,7,10}$ was not associated with annual change in $\mathrm{LAV}_{\%}$ or $\mathrm{FEV}_{1.0}$.

Conclusion: Progression of osteoporosis and that of COPD are not directly related or synchronized with each other.

Keywords: osteoporosis, quantitative $\mathrm{CT}$ analysis, $\mathrm{FEV}_{1.0}$, low attenuation volume, automatic analysis, systemic effect

\section{Introduction}

COPD is characterized by progressive airflow limitation caused by enhanced chronic inflammatory response of the airways and lungs to cigarette smoke. Comorbidities of COPD have recently attracted considerable attention because they have a great impact on disease severity and prognosis and the quality of life of patients. ${ }^{1}$ While some comorbidities may arise from shared risk factors, others may be influenced by the features of COPD, ${ }^{2}$ such as systemic inflammation. ${ }^{1}$

Osteoporosis is a well-known comorbidity in COPD. It is associated with poor health status and prognosis. In patients with COPD, osteoporosis has been reported to be associated with age, low body mass index (BMI), tobacco exposure, physical inactivity,
Correspondence: Yasutaka Nakan Department of Medicine, Shiga University of Medical Science, Seta Tsukinowa-cho, Otsu, Shiga 520-2192, Japan

Tel +8I 775482213

Fax +8I 775435839

Email nakano@belle.shiga-med.ac.jp 
systemic inflammation, intake of corticosteroids, extent of emphysematous lesions, and $\mathrm{FEV}_{1.0}{ }^{3-6}$ Although the mechanisms associated with osteoporosis and COPD are not entirely clear, osteoporosis is suggested to be either a comorbidity due to shared risk factors (eg, age and smoking habits) or a systemic effect of COPD with a cause-effect relationship. ${ }^{7}$

Emphysematous lesions assessed by computed tomography $(\mathrm{CT})$ and $\mathrm{FEV}_{1.0}$ are important indices of COPD which correlate with the severity of COPD and mortality. ${ }^{8}$ Several cross-sectional studies have shown the association of bone mineral density (BMD) with $\mathrm{FEV}_{1.0}$ and emphysematous lesions in patients with COPD..$^{3-4,7,9-12}$

In this study, we evaluated whether progression of osteoporosis is synchronized with that of COPD. The relationship of annual change in BMD with annual changes in pulmonary function and emphysematous lesions was evaluated.

\section{Materials and methods Study design and subjects}

This study used data from the Hokkaido COPD cohort study. The aims and design of the Hokkaido COPD cohort study have been described elsewhere. ${ }^{13}$ In brief, the participants fulfilled the spirometric criteria presented in the Global Initiative for Chronic Obstructive Lung Disease (GOLD) documents (ratio of post-bronchodilator $\mathrm{FEV}_{1.0}$ to $\mathrm{FVC}<0.70$ ) more than once within a year from the first visit. ${ }^{1}$ The inclusion criteria were the following: (1) diagnosis of COPD by a pulmonologist; (2) current or former smoker with a smoking history of at least 10 pack-years; (3) age $\geq 40$ years; and (4) willingness to provide written informed consent. The exclusion criteria were the following: (1) diagnosis of bronchial asthma, bronchiectasis, or bullous lung disease; (2) presence of active tuberculosis; (3) history of lung cancer, cystic fibrosis, allergic alveolitis, or pulmonary fibrosis; (4) history of lung resection; (5) long-term oxygen therapy for $12 \mathrm{~h}$ or more per day; (6) exacerbation experienced within a month before enrollment for visit 1; and (7) withdrawal of consent. ${ }^{13}$ In the present study, 105 patients who underwent chest CT at least twice between June 2003 and October 2006 at the Hokkaido University Hospital were enrolled. Of the 411 CT images of the 105 patients, 28 images were found to be ineligible for measurement of vertebral bone attenuation; in addition, two patients were excluded because some of their CT images were found to be ineligible. As a result, this study included 383 CT images from 103 patients (Figure 1).

The study was approved by the ethics committee of Hokkaido University and conformed to the tenets of the Declaration of Helsinki, and all participants provided written informed consent.

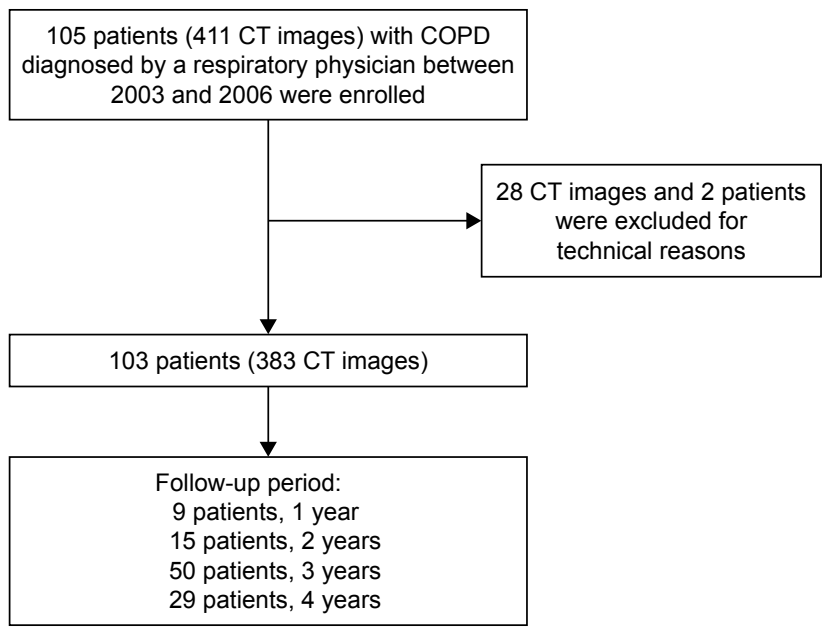

Figure I Patient disposition and reasons for exclusion.

\section{Assessment of clinical parameters}

Data regarding gender, age, height, weight, smoking and medical history, medication, and pulmonary symptoms were recorded at the first visit. Changes in smoking status, medical history, and pharmacotherapy were monitored every 6 months. Health-related quality of life was assessed every year using St George's Respiratory Questionnaire (SGRQ). Blood tests were performed every year for evaluation of circulating blood cell counts and serum immunoglobulin $\mathrm{E}$ (IgE) and C-reactive protein (CRP) concentrations.

\section{Pulmonary function tests and CT}

We confirmed that all respiratory medicines were discontinued before evaluation. Spirometry was conducted on every visit, before and after inhalation of a bronchodilator. Predicted values of spirometric measurements were derived from the guidelines for pulmonary function tests issued by the Japanese Respiratory Society. ${ }^{14}$ Chest CT images were acquired at full inspiration in the supine position. Computerized three-dimensional CT analysis of the lungs was performed using custom software, and the extent of emphysema was expressed as the percentage of low attenuation volume $<-950$ Hounsfield units (HU) (LAV\%). ${ }^{13,15}$ Airway lesions were assessed by measuring the square root of airway wall area of the hypothetical airway with an internal perimeter of $10 \mathrm{~mm}$ ( $\sqrt{\text { Aaw }}$ at Pi10), which is a standardized index of airway wall thickness, using Apollo ${ }^{\circledR}$ software (VIDA Diagnostics, Coralville, IA, USA). ${ }^{16-19}$

\section{Measurement of CT attenuation of thoracic vertebral bone}

Using the custom software, ${ }^{20,21} \mathrm{CT}$ attenuation values of all thoracic vertebral bodies were measured (Figure 2). 

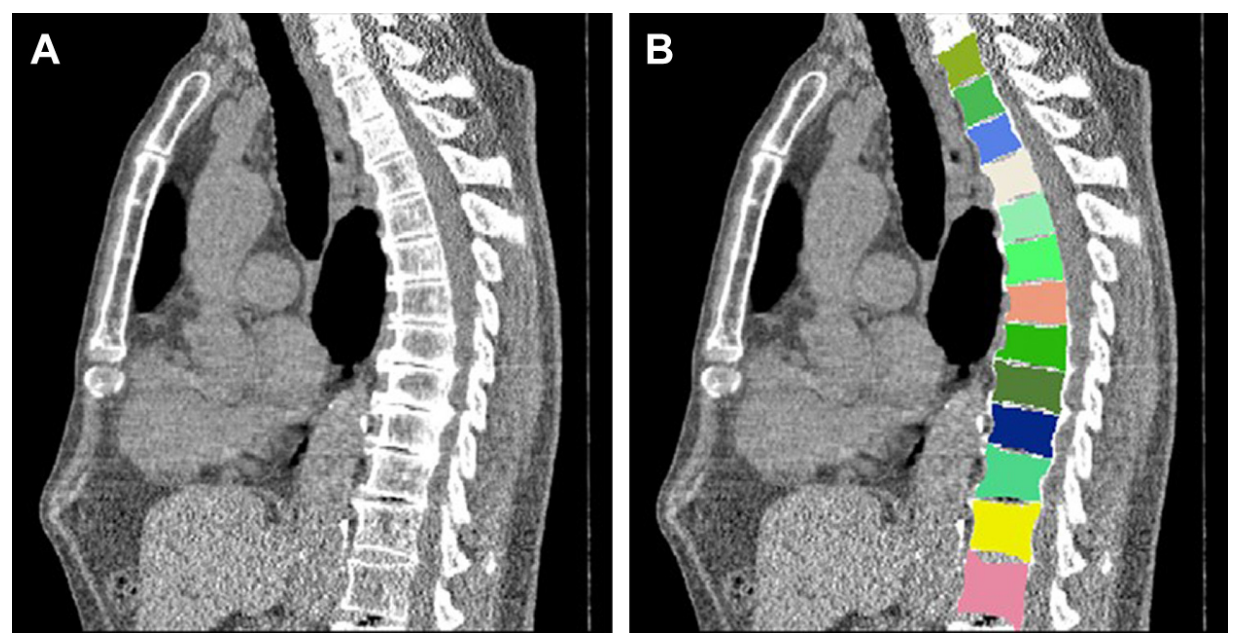

Figure 2 Images of thoracic vertebral bodies for measurement of computed tomography attenuation.

Notes: (A) Sagittal image of thoracic vertebral bodies. (B) Images of identified thoracic vertebral bodies. Each vertebrae was automatically identified and painted using different colors.

The software contains an algorithm for the automatic extraction of vertebral bodies and the measurement of bone densities. The average bone densities of thoracic vertebrae 4, 7, and $10\left(\mathrm{ABD}_{4,7,10}\right)$ and of all thoracic vertebrae $\left(\mathrm{ABD}_{1-12}\right)$ were calculated and expressed in HU.

\section{Statistical analyses}

All statistical analyses were performed using JMP9.0.2 $2^{\circledR}$ software (SAS Institute, Cary, NC, USA). Relationships among the variables were assessed by Spearman's rank correlation test. Multivariate regression analysis was performed to evaluate the relative contributions of associated factors to $\mathrm{ABD}_{4,7,10^{*}}$. A mixed-effects model was used for the evaluation of data on all subjects (103 patients). The best linear unbiased predictions of annual changes in $\mathrm{FEV}_{1.0}\left(\Delta \mathrm{FEV}_{1.0} ; \mathrm{mL} /\right.$ year $), \mathrm{LAV}^{\circ}$ $\left(\triangle \mathrm{LAV} \%, \% /\right.$ year), and $\mathrm{ABD}_{4,7,10}\left(\Delta \mathrm{ABD}_{4,7,10} ; \mathrm{HU} /\right.$ year $)$ were estimated using a random coefficient regression model. We considered $p$-values $<0.05$ to be statistically significant.

\section{Results}

\section{Patient characteristics}

Table 1 presents the characteristics of the 103 included patients. Seven patients $(6.8 \%)$ were female, and the median follow-up period was 3 years. With regard to osteoporosis treatment, two patients were prescribed vitamin $\mathrm{D}$, and none was prescribed bisphosphonate at the first visit. There was no change in the prescription for osteoporosis treatment during the study period.

\section{Relationship between baseline ABD and other variables}

$\mathrm{ABD}_{4,7,10}$ and $\mathrm{ABD}_{1-12}$ correlated well $(\rho=0.982 ; p<0.001)$. However, neither $\mathrm{ABD}_{4,7,10}$ nor $\mathrm{ABD}_{1-12}$ was associated
Table I Patient characteristics ( $\mathrm{N}=103)$

\begin{tabular}{|c|c|}
\hline Characteristic & \\
\hline Age (years) & $69.8 \pm 7.8$ \\
\hline Gender (female/male) & $7 / 96$ \\
\hline Current smoking status at enrolment & $26(25.2)$ \\
\hline Smoking history (pack-years) & $61.4 \pm 27.8$ \\
\hline Follow-up period (years) $(1 / 2 / 3 / 4)$ & $9 / 15 / 50 / 29$ \\
\hline BMI $\left(\mathrm{kg} / \mathrm{m}^{2}\right)$ & $22.7 \pm 3.0(n=100)$ \\
\hline MRC dyspnea score $(0 / 1 / 2 / 3 / 4 / 5)$ & $8 / 12 / 37 / 44 / 1 / 1$ \\
\hline SGRQ activity score & $41.4 \pm 22.4$ \\
\hline \multicolumn{2}{|l|}{ Osteoporosis medication } \\
\hline Vitamin D & $2(1.9)$ \\
\hline \multicolumn{2}{|l|}{ Laboratory tests } \\
\hline White blood cell count (cells $/ \mathrm{m}^{2}$ ) & $6,505 \pm I, 674$ \\
\hline Neutrophil count (cells/m²) & $3,804 \pm I, 378$ \\
\hline Eosinophil count (cells $\left./ \mathrm{m}^{2}\right)$ & $204 \pm 145$ \\
\hline $\mathrm{CRP}(\mathrm{mg} / \mathrm{dL})$ & $0.34 \pm 0.43(n=100)$ \\
\hline $\lg E(I U / m L)$ & $2|2.1 \pm 65| .2(n=88)$ \\
\hline \multicolumn{2}{|l|}{ Lung function tests } \\
\hline $\mathrm{FEV}_{1.0}(\mathrm{~L})$ & $\mathrm{I} .8 \mathrm{I} \pm 0.66$ \\
\hline \%FEV $_{1.0}$ & $66.8 \pm 20.2$ \\
\hline $\mathrm{FEV}_{10} / \mathrm{FVC}$ & $0.52 \pm 0.12$ \\
\hline GOLD stage $(0 / 1 / 2 / 3 / 4)$ & $7 / 25 / 48 / 21 / 2$ \\
\hline LAV\% & $24.6 \pm 13.9(n=102)$ \\
\hline$\sqrt{ }$ Aaw at $\mathrm{Pil} 0(\mathrm{~mm})$ & $3.98 \pm 0.07(n=94)$ \\
\hline $\mathrm{ABD}_{4,7,10}(\mathrm{HU})$ & $132.2 \pm 43.1$ \\
\hline $\mathrm{ABD}_{1-12}(\mathrm{HU})$ & $138.0 \pm 43.0$ \\
\hline$\Delta \mathrm{ABD}_{4,7,10}(\mathrm{HU})$ & $3.07 \pm 3.02$ \\
\hline$\Delta \mathrm{ABD}_{1-12}^{4,+10}(\mathrm{HU})$ & $2.91 \pm 2.67$ \\
\hline$\Delta \mathrm{FEV}_{1.0}(\mathrm{~mL})$ & $23.0 \pm 22.0$ \\
\hline$\Delta \mathrm{LAV} \%$ & $0.69 \pm 0.46$ \\
\hline
\end{tabular}

Note: Data are expressed as mean \pm SD or $\mathrm{n}(\%)$.

Abbreviations: BMI, body mass index; MRC, Medical Research Council; SGRQ, St George's Respiratory Questionnaire; CRP, C-reactive protein; IgE, immunoglobulin E; \% FEV ${ }_{1.0}$, percentage of $\mathrm{FEV}_{1.0}$ predicted in accordance with the guidelines for pulmonary function tests issued by the Japanese Respiratory Society; GOLD, Global Initiative for Chronic Obstructive Lung Disease; LAV\%, percentage of low attenuation volume; $\sqrt{ }$ Aaw at Pil0, square root of airway wall area of the hypothetical airway with an internal perimeter of $10 \mathrm{~mm}$; $A B D$, average vertebral bone density; $\mathrm{HU}$, Hounsfield unit; $A B D_{4,7,10}$, average bone densities of thoracic vertebrae 4,7 , and $10 ; \mathrm{ABD}_{1-12}$, average bone densities of all thoracic vertebrae; $\Delta$, annual change in each variable. 
Table 2 Association between ABD and other evaluated variables

\begin{tabular}{|c|c|c|c|c|}
\hline \multirow[t]{2}{*}{ Factor } & \multicolumn{2}{|c|}{$\mathrm{ABD}_{4,7,10}$} & \multicolumn{2}{|c|}{$A B D_{1-12}$} \\
\hline & $\rho$ & $p$-value & $\rho$ & $p$-value \\
\hline Age & -0.331 & $0.0006 *$ & -0.317 & $0.0011 *$ \\
\hline $\mathrm{BMI}$ & 0.246 & $0.0136 *$ & 0.236 & $0.0179 *$ \\
\hline Smoking history & -0.004 & 0.9718 & 0.029 & 0.7728 \\
\hline SGRQ activity score & -0.248 & $0.0115^{*}$ & -0.261 & $0.0078^{*}$ \\
\hline White blood cell count & 0.082 & 0.4117 & 0.089 & 0.3693 \\
\hline Neutrophil count & 0.017 & 0.867 & 0.02 & 0.8452 \\
\hline Eosinophil count & 0.229 & $0.0198 *$ & 0.234 & $0.0175^{*}$ \\
\hline $\mathrm{Hb}$ & 0.132 & 0.1826 & 0.102 & 0.3034 \\
\hline CRP & -0.023 & 0.8209 & -0.02 & 0.8455 \\
\hline $\lg \mathrm{E}$ & 0.019 & 0.8622 & 0.036 & 0.7361 \\
\hline $\mathrm{FEV}_{1.0}(\mathrm{~L})$ & 0.179 & 0.0713 & 0.168 & 0.0906 \\
\hline$\% \mathrm{FEV}_{1.0}$ & 0.125 & 0.2092 & 0.112 & 0.2607 \\
\hline $\mathrm{FEV}_{1.0} / \mathrm{FVC}$ & 0.17 & 0.0857 & 0.139 & 0.1626 \\
\hline FVC & 0.129 & 0.1929 & 0.142 & 0.1517 \\
\hline LAV\% & -0.372 & $0.0001 *$ & -0.367 & $0.000 I^{*}$ \\
\hline$\sqrt{ }$ Aaw at Pil0 & 0.099 & 0.345 & 0.103 & 0.3213 \\
\hline \multicolumn{5}{|l|}{ Annual change } \\
\hline$\Delta \mathrm{FEV}_{1.0}$ & 0.12 & 0.2263 & 0.106 & 0.2866 \\
\hline$\Delta \mathrm{LAV} \%$ & 0.08 & $0.424 I$ & 0.088 & 0.3788 \\
\hline
\end{tabular}

Notes: Relationships were assessed by Spearman's rank correlation test. *Significant difference $(p<0.05)$.

Abbreviations: $A B D$, average vertebral bone density; $A B D_{4,7,10}$, average bone densities of thoracic vertebrae 4,7 , and $10 ; A_{1-12}$, average bone densities of all thoracic vertebrae; BMI, body mass index; SGRQ, St George's Respiratory Questionnaire; Hb, hemoglobin; CRP, C-reactive protein; IgE, immunoglobulin E; $\% \mathrm{FEV}_{1,0}$, percentage of $\mathrm{FEV}$, predicted in accordance with the guidelines for pulmonary function tests issued by the Japanese Respiratory Society; LAV\%, percentage of low attenuation volume; $\sqrt{ }$ Aaw at $\mathrm{Pi} I 0$, square root of airway wall area of the hypothetical airway with an internal perimeter of $10 \mathrm{~mm} ; \Delta$, annual change in each variable.

with $\mathrm{FEV}_{1.0}$, annual change in $\mathrm{LAV} \%(\Delta \mathrm{LAV} \%)$, or $\mathrm{FEV}_{1.0}$ $\left(\triangle \mathrm{FEV}_{1.0}\right)$. As shown in Table $2, \mathrm{ABD}_{4,7,10}$ at baseline was significantly correlated with age $(\rho=-0.331 ; p=0.0006)$, BMI $(\rho=0.246 ; p=0.0136)$, SGRQ activity score $(\rho=-0.248$; $p=0.0115)$, eosinophil count $(\rho=0.229 ; p=0.0198)$, and LAV\% $(\rho=-0.372 ; p=0.0001)$. Similarly to $\mathrm{ABD}_{4,7,10}$, $\mathrm{ABD}_{1-12}$ exhibited significant relationships with age, BMI, SGRQ activity score, eosinophil count, and LAV\%. After adjustment for age, BMI, SGRQ activity score, and eosinophil count (variables which exhibited significant correlation with baseline $\mathrm{ABD}_{4,7,10}$ ), the correlation between $\mathrm{ABD}_{4,7,10}$ and LAV\% was no longer significant (Table 3).

Table 3 Relative contribution of each variable for prediction of $\mathrm{ABD}_{4,7,10}$

\begin{tabular}{lll}
\hline Factor & $\boldsymbol{t}$ & $\boldsymbol{p}$-value \\
\hline LAV\% & -0.48 & 0.6305 \\
Age & -3.15 & $0.0022^{*}$ \\
BMI & 2.56 & $0.012^{*}$ \\
SGRQ activity score & -0.67 & 0.504 \\
Eosinophil count & 1.18 & 0.2392 \\
\hline
\end{tabular}

Notes: LAV\%, age, BMI, SGRQ activity score, and eosinophil count were included as candidate-independent variables. *Significant difference $(p<0.05)$.

Abbreviations: $A_{B D}$, 1,10 , average bone density of thoracic vertebrae 4,7 , and 10; LAV\%, percentage of low attenuation volume; BMI, body mass index; SGRQ, St George's Respiratory Questionnaire.
Table 4 Association between $\triangle A B D$ and each variable

\begin{tabular}{|c|c|c|c|c|}
\hline \multirow[t]{2}{*}{ Factor } & \multicolumn{2}{|c|}{$\Delta \mathbf{A B D}_{4,7,10}$} & \multicolumn{2}{|c|}{$\triangle A B D_{1-12}$} \\
\hline & $\rho$ & $p$-value & $\rho$ & $p$-value \\
\hline \multicolumn{5}{|l|}{ Baseline } \\
\hline Age & 0.094 & 0.345 & 0.092 & 0.3539 \\
\hline BMI & 0.099 & 0.3269 & 0.155 & 0.1243 \\
\hline Pack-year & 0.058 & 0.5606 & 0.038 & 0.7066 \\
\hline SGRQ activity score & -0.127 & 0.2015 & -0.083 & 0.4022 \\
\hline White blood cell count & -0.054 & 0.5852 & -0.009 & 0.9286 \\
\hline Neutrophil count & -0.099 & 0.3227 & -0.069 & 0.488 \\
\hline Eosinophil count & 0.053 & 0.5945 & 0.034 & 0.7365 \\
\hline Hemoglobin & 0.133 & 0.1809 & 0.131 & 0.1864 \\
\hline CRP & 0.031 & 0.7616 & 0.077 & 0.4469 \\
\hline $\lg \mathrm{E}$ & 0.037 & 0.7312 & 0.059 & 0.5838 \\
\hline $\mathrm{FEV}_{1.0}$ & 0.066 & 0.506 & 0.059 & 0.5567 \\
\hline$\% \mathrm{FEV}_{1.0}$ & 0.024 & 0.8098 & 0.034 & 0.7355 \\
\hline $\mathrm{FEV}_{1.0} / \mathrm{FVC}$ & 0.049 & 0.6267 & 0.058 & 0.5643 \\
\hline FVC & 0.084 & 0.4008 & 0.042 & 0.6756 \\
\hline LAV\% & -0.011 & 0.9107 & -0.023 & 0.8218 \\
\hline$\sqrt{ }$ Aaw at Pil0 & -0.032 & 0.763 & -0.018 & 0.86 \\
\hline \multicolumn{5}{|l|}{ Annual change } \\
\hline$\Delta \mathrm{FEV}_{1.0}$ & 0.092 & 0.3531 & 0.144 & 0.1482 \\
\hline$\Delta \mathrm{LAV} \%$ & -0.021 & 0.8339 & -0.073 & 0.4616 \\
\hline
\end{tabular}

Note: Relationships were assessed by Spearman's rank correlation test.

Abbreviations: $A B D$, average vertebral bone density; $A B D_{4.7 .10}$, average bone densities of thoracic vertebrae 4,7 , and $10 ; A B D_{1-12}$, average bone densities of all thoracic vertebrae; BMI, body mass index; SGRQ, St George's Respiratory Questionnaire; CRP, C-reactive protein; IgE, immunoglobulin E; \% FEV ${ }_{10}$, percentage of $\mathrm{FEV}_{1.0}$ predicted in accordance with the guidelines for pulmonary function tests issued by the Japanese Respiratory Society; LAV\%, percentage of low attenuation volume; $\Delta$, annual change in each variable.

\section{Relationship between $\triangle \mathrm{ABD}$ and other variables}

As shown in Table $4, \triangle \mathrm{ABD}_{4,7,10}$ was not associated with age, BMI, $\mathrm{FEV}_{1.0}, \Delta \mathrm{FEV}_{1.0}, \mathrm{LAV} \%, \Delta \mathrm{LAV} \%$, or systemic inflammatory factors such as white blood cell count and CRP concentration.

\section{Discussion}

In this study, annual change in $\mathrm{ABD}$ was not associated with that in $\mathrm{LAV} \%$ or $\mathrm{FEV}_{1.0}$ in patients with COPD. At the first visit, ABD was associated with LAV\%, which is consistent with the findings of previous studies. ${ }^{7,10,22}$ However, after adjustment for age, BMI, physical activity, and eosinophil count, $\mathrm{LAV} \%$ was no longer associated with $\mathrm{ABD}_{4,7,10^{\circ}}$. Our findings suggest that progression of osteoporosis and COPD are not synchronized with each other.

Only a few studies have examined the association of annual change in BMD with that in emphysematous lesions or $\mathrm{FEV}_{1.0}$. Kiyokawa et al observed 42 patients with COPD without osteoporosis treatment for 2 years and concluded that annual change in BMD was not associated with that in low attenuation area percentage or $\mathrm{FEV}_{10}{ }^{22}$ The present findings, 
which were obtained with a greater number of patients and longer follow-up periods, using a mixed-effects model, help to confirm these previous results.

Several cross-sectional studies have used multivariate models to demonstrate that emphysematous lesions are significantly correlated with BMD in patients with COPD even after adjustment for age, BMI, smoking index, $\mathrm{FEV}_{1.0}$, and partial pressure of oxygen in arterial blood., ${ }^{7,12}$ Bon demonstrated in a cross-sectional study that radiographically evaluated emphysema is a strong, independent predictor of low BMD in current and former smokers. ${ }^{11}$ Unlike in the present study, the previous author evaluated BMD by dual-energy X-ray absorptiometry and emphysematous change by visual assessment. It has been reported that BMI is negatively correlated with LAV\% but not with airway lesions. ${ }^{23}$ In this study, $\sqrt{ }$ Aaw at Pi10 did not correlate with ABD. This is the only study examining the association between $\sqrt{ }$ Aaw at Pi10 and BMD. ${ }^{12}$

Although both BMI and LAV\% are correlated with ABD, LAV\% was not correlated with ABD after adjustment for BMI. Thus, low BMI may influence both emphysema and osteoporosis in patients with COPD. In this study, eosinophil count was positively associated with $\mathrm{ABD}$; however, after adjustment for age, BMI, SGRQ activity score, and LAV\%, this association was no longer apparent. We excluded patients with clinically diagnosed bronchial asthma in this study. We have previously demonstrated that eosinophil count is negatively correlated with annual decline in $\mathrm{FEV}_{1.0}{ }^{24}$ Patients with COPD with high eosinophil counts may exhibit a different phenotype from patients without high eosinophil counts. Further study is needed.

In this study, we used custom software for measuring bone CT attenuation. Takahashi et al validated this software in 526 cases and found that bone CT attenuation was strongly corrected with dual-energy X-ray absorptiometry-measured $\operatorname{BMD}\left(R^{2}=0.829\right)$ in patients with COPD. ${ }^{20,21}$

Some studies on the assessment of bone health status in patients with COPD by measurement of CT bone attenuation have considered the average attenuation values of thoracic vertebrae 4,7 , and $10\left(\mathrm{ABD}_{4,7,10}\right)$ for analysis. ${ }^{7,10,22,25}$ In the present study, we additionally measured the average attenuation values of all vertebrae $\left(\mathrm{ABD}_{1-12}\right)$. Our results demonstrated that $\mathrm{ABD}_{4,7,10}$ and $\mathrm{ABD}_{1-12}$ correlated well $(\rho=0.982 ; p<0.001)$. Thus, we thought it sufficient to use $\mathrm{ABD}_{4,7,10}$, a previously used parameter, ${ }^{7,10,22,26}$ in the measurement of BMD.

Only a few studies have reported on osteoporosis medications for patients with COPD. In previous studies, bisphosphonate was prescribed to $5.8 \%$ of 190 smokers and $5.7 \%$ and $7 \%$ of 210 and 658 patients with COPD, $, 3,12,27$ respectively. In the present study, none of the patients was prescribed bisphosphonate, and only two patients were prescribed vitamin D. Systemic corticosteroids also affect BMD. ${ }^{5}$ In this study, seven out of 103 patients used inhaled corticosteroids (ICS) and one patient used oral corticosteroids at entry to this study. Eighteen patients began to use ICS and five patients began to use oral corticosteroids after study entry. We excluded these patients and reanalyzed the data. However, the main results did not change.

In this study, seven female patients were included. Since gender differences may affect the correlations between ABD and COPD parameters, ${ }^{5}$ we excluded the female patients and analyzed the 96 male patients. The relationships between $\mathrm{ABD}$ or $\triangle \mathrm{ABD}$ and other parameters did not change.

This study has several limitations. First, details regarding prescribed medicines, except for those prescribed for COPD treatment, were not fully available. However, as described in "Patient characteristics" in the Results section, we were able to collect data regarding osteoporosis medications.

Second, clinical data regarding vertebral compression fractures were lacking. It has been reported that CT scan density showed a highly significant positive correlation with pathological measurements of vertebral bone density. ${ }^{22}$ However, fracture and deformation of vertebral bodies could affect the ABD. While most of the previous studies on COPD and osteoporosis have not referred to vertebral compression fractures, $3,7,9,10,22,25$ the TOwards a Revolution in COPD Health study reported a low incidence of fractures $(5.1 \%-6.3 \%)$ in patients with COPD during the 3 year study period. ${ }^{27}$ Thus, in this study, we visually assessed all CT images for signs of vertebral fracture and found no such instances. In addition, we used our custom software, ${ }^{20,21}$ and measured the height of each vertebral body in all subjects. We found three subjects whose vertebral bodies showed more than $20 \%$ decrease in height compared with the adjacent vertebral bodies. We then excluded these three subjects from the analysis, but the main result did not change.

Third, the disease duration of COPD may affect ABD. However, we do not have the data about the duration of COPD. Further study is needed to clarify this point.

Notwithstanding the several limitations, the patients were followed up for as long as 4 years, and the median follow-up period was 3 years, which is longer than that

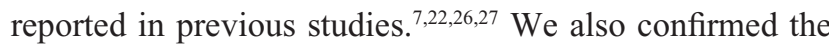
present results by evaluating the data on 79 other patients, who were followed up for 3 years or more; the results of both study cohorts were the same. By evaluating a total of $383 \mathrm{CT}$ images (an average of $3.72 \mathrm{CT}$ images per patient), we were able to calculate the annual changes in $\mathrm{ABD}, \mathrm{LAV} \%$, and $\mathrm{FEV}_{1.0}$ using a mixed-effects model. 


\section{Conclusion}

Progression of osteoporosis and that of COPD are not directly correlated or synchronized with each other.

\section{Acknowledgments}

This study was supported by a scientific research grant from the Ministry of Education Science, Culture and Sports of Japan (17390239 and 2139053); a grant to the Respiratory Failure Research Group from the Ministry of Health, Labor and Welfare, Japan; Nippon Boehringer Ingelheim; Pfizer, Inc.; Daiichi Sankyo Co. Ltd; and Chugai Pharmaceutical Co., Ltd. The sponsor of the study had no role in study design, data collection, data analysis, data interpretation, or writing of the report. We would like to thank Editage (www.editage.jp) for English language editing.

\section{Disclosure}

The authors report no conflicts of interest in this work.

\section{References}

1. From the Global Strategy for the Diagnosis, Management and Prevention of COPD. Global Initiative for Chronic Obstructive Lung Disease (GOLD) 2017. Available from: http://www.goldcopd.org. Accessed October 09, 2017.

2. Soriano JB, Visick GT, Muelleorova H, Payvandi N, Hansell AL. Patterns of comorbidities in newly diagnosed COPD and asthma in primary care. Chest. 2005;128:2099-2107.

3. Bon J, Fuhrman CR, Weissfeld JL, et al. Radiographic emphysema predicts low bone mineral density in a tobacco-exposed cohort. Am J Respir Crit Care Med. 2011;183:885-890.

4. Duckers JM, Evans BAJ, Fraser WD, Stone MD, Bolton CE, Shale DJ. Low bone mineral density in men with chronic obstructive pulmonary disease. Respir Res. 2011;12:101.

5. Lehouck A, Boonen S, Decramer M, Janssens W. COPD, bone metabolism, and osteoporosis. Chest. 2011;139:648-657.

6. Romme EAPM, Smeenk FWJM, Rutten EPA, Wouters EFM. Osteoporosis in chronic obstructive pulmonary disease. Expert Rev Respir Med. 2013;7:397-410.

7. Romme EAPM, Murchison JT, Edwards LD, et al. CT-measured bone attenuation in patients with chronic obstructive pulmonary disease: relation to clinical features and outcomes. J Bone Miner Res. 2013;28: 1369-1377.

8. Haruna A, Muro S, Nakano Y, et al. CT scan findings of emphysema predict mortality in COPD. Chest. 2010;138:635-640.

9. Miller J, Edwards LD, Agustí A, et al. Comorbidity, systemic inflammation and outcomes in the ECLIPSE cohort. Respir Med. 2013;107: $1376-1384$.

10. Ohara T, Hirai T, Muro S, et al. Relationship between pulmonary emphysema and osteoporosis assessed by CT in patients with COPD. Chest. 2008;134:1244-1249.

International Journal of COPD

\section{Publish your work in this journal}

The International Journal of COPD is an international, peer-reviewed journal of therapeutics and pharmacology focusing on concise rapid reporting of clinical studies and reviews in COPD. Special focus is given to the pathophysiological processes underlying the disease, intervention programs, patient focused education, and self management protocols.
11. Bon J. Does radiographic emphysema correlate with low bone mineral density? Curr Opin Pulm Med. 2012;18:125-130.

12. Chubachi S, Nakamura H, Sasaki M, et al. Polymorphism of LRP5 gene and emphysema severity are associated with osteoporosis in Japanese patients with or at risk for COPD. Respirology. 2015;20:286-295.

13. Nishimura M, Makita H, Nagai K, et al. Annual change in pulmonary function and clinical phenotype in chronic obstructive pulmonary disease. Am J Respir Crit Care Med. 2012;185:44-52.

14. [Guideline of respiratory function tests - spirometry, flow-volume curve, diffusion capacity of the lung]. Nihon Kokyuki Gakkai Zasshi. 2004;Suppl:1-56. Japanese.

15. Park KJ, Bergin CJ, Clausen JL. Quantitation of emphysema with three-dimensional CT densitometry: comparison with two-dimensional analysis, visual emphysema scores, and pulmonary function test results. Radiology. 1999;211:541-547.

16. Tho NV, Trang le TH, Murakami Y, et al. Airway wall area derived from 3-dimensional computed tomography analysis differs among lung lobes in male smokers. PLoS One. 2014;9(5):e98335.

17. Nakano Y, Wong JC, de Jong PA, et al. The prediction of small airway dimensions using computed tomography. Am J Respir Crit Care Med. 2005;171:142-146.

18. Gietema, HA, Müller NL, Fauerbach PV, et al. Quantifying the extent of emphysema: factors associated with radiologists' estimations and quantitative indices of emphysema severity using the ECLIPSE cohort. Acad Radiol. 2011;18:661-671.

19. Van Tho N, Ogawa E, Trang le TH, et al. A mixed phenotype of airway wall thickening and emphysema is associated with dyspnea and hospitalization for chronic obstructive pulmonary disease. Ann Am Thorac Soc. 2015;12:988-996.

20. Takahashi E, Suzuki H, Kawata Y, et al. Computer aided diagnosis for osteoporosis using chest multi-slice CT images. IEICE Trans Inf Syst. 2013;96:892-900.

21. Takahashi E, Kawata Y, Niki N, Nakano Y, Harada M, Moriyama N. Computer aided diagnosis for osteoporosis based on vertebral column structure analysis. Proc SPIE, 8315, Medical Imaging 2012: ComputerAided Diagnosis, 831533 (February 23, 2012).

22. Kiyokawa H, Muro S, Oguma T, et al. Impact of COPD exacerbations on osteoporosis assessed by chest CT scan. COPD. 2012:9:235-242.

23. Ogawa E, Nakano Y, Ohara T, et al. Body mass index in male patients with COPD: correlation with low attenuation areas on CT. Thorax. 2009;64:20-25.

24. Suzuki M, Makita H, Konnno S, Shimizu K, Kimura H, Nishimura M. Asthma-like features and clinical course of chronic obstructive pulmonary disease. An analysis from the Hokkaido COPD cohort study. Am J Respir Crit Care Med. 2016;194:1358-1365.

25. Romme EA, Murchison JT, Phang KF, et al. Bone attenuation on routine chest CT correlates with bone mineral density on DXA in patients with COPD. J Bone Miner Res. 2012;27:2338-2343.

26. Graat-Verboom L, Smeenk SW, van den Borne BE, et al. Progression of osteoporosis in patients with COPD: a 3-year follow up study. Respir Med. 2012;106:861-870.

27. Ferguson GT, Calverly PM, Anderson JA, et al. Prevalence and progression of osteoporosis in patients with COPD: results from the TOwards a Revolution in COPD Health study. Chest. 2009;136:1456-1465.

This journal is indexed on PubMed Central, MedLine and CAS. The manuscript management system is completely online and includes a very quick and fair peer-review system, which is all easy to use. Visit $\mathrm{http} / / / \mathrm{www}$.dovepress.com/testimonials.php to read real quotes from published authors. 